\title{
Fanconi Anemia Complementation Group C Is Required for Proliferation of Murine Primordial Germ Cells
}

\author{
Jessica J. Nadler and Robert E. Braun* \\ Department of Genetics, University of Washington, Seattle, Washington
}

Received 23 May 2000; Accepted 30 June 2000

\begin{abstract}
Summary: Fanconi anemia is a polygenic trait hypothesized to be a DNA damage repair disease. We show that all three Fanconi anemia loci that have been cloned are expressed in the embryonic gonad during the period of primordial germ cell proliferation. Mice mutant for the Fanconi anemia complementation group C locus (Fancc) have reduced germ cell numbers as early as embryonic day E12.5, suggesting the Fancc protein functions prior to meiosis in both sexes. Depletion in the mutant occurs at a time when all three loci would be expressed in a wild-type gonad, implying a function in the early germline. Determination of the mitotic index of primordial germ cells by BrdU incorporation shows that germ cells in Fancc $^{-/-}$mice proliferate significantly more slowly than littermate controls. This study demonstrates Fancc is required for mitotic proliferation of primordial germ cells. genesis 27:117-123, 2000. @ 2000 Wiley-Liss, Inc.
\end{abstract}

Maintenance of a totipotent germ cell lineage capable of undergoing gametogenesis is critical for reproduction. In the mammalian embryo, cells that will later develop into either sperm or eggs undergo a lineage restriction from a pool of equipotential neighbors. A small population of primordial germ cells (PGCs) are first detectable enzymatically at E7.2 due to their high levels of alkaline phosphatase activity (Lawson and Hage, 1994). Specified PGCs migrate from their extraembryonic location at the base of the allantois to the genital ridge between E8.5 and E13.5. PGC proliferation continues during cell migration to produce approximately 20,000 germ cells in each ridge (De Felici and McLaren, 1982). At E13.5, female PGCs replicate their DNA and enter meiosis I, while males arrest in mitosis (McLaren, 1984). Few of the genes required for specification, migration, or proliferation have been identified. Bmp4 is critical for the allocation of PGCs in the mouse embryo (Lawson et al., 1999) and Steel factor and its receptor, c-kit, are important for survival of PGCs (Matsui et al., 1991). A gene first characterized as a human disease gene, Fanconi anemia complementation group C (Fancc), is implicated in prenatal germ cell development (Whitney et al., 1996).

Fanconi anemia (FA) is inherited as a recessive disorder. Its main symptom is pancytopenia, a progressive loss of all blood cell types. The cellular phenotype of FA is a $G_{2}$ to $M$ cell cycle delay and hypersensitivity to DNA crosslinking agents, such as mitomycin $\mathrm{C}$ and diepoxybutane (Strathdee et al., 1992). Mutations in as many as eight different genes cause Fanconi Anemia. Gene products have been cloned for three of the eight defined complementation groups, A, C, and G (de Winter et al., 1998; Foe et al., 1996; Wevrick et al., 1993). The genes encode proteins lacking homology to each other or any known proteins. Human FANCA, FANCC and FANCG associate and function as a nuclear complex (GarciaHiguera et al., 1999).

The Fancc cDNA was cloned by its ability to rescue the mitomycin C sensitivity of a human FA lymphoblast cell line(Wevrick et al., 1993). The cDNA encodes a $63-\mathrm{kD}$ protein present mainly in the cytoplasm, with a fraction recruited to the nucleus through interaction with FANCA (Kupfer et al., 1997). Examination of the transcript during mouse development by in situ hybridization has shown ubiquitous expression, with higher levels in less differentiated tissues (Krasnoshtein and Buchwald, 1996). Animals carrying a targeted allele of Fancc exhibit no spontaneous somatic phenotype, although anemia can be induced by treatment with mitomycin C (Carreau et al., 1998). Surprisingly, Fancc ${ }^{-1-}$ females are sterile and males have reduced fertility. By postpartum day one, germ cell numbers are dramatically reduced in both sexes (Chen et al., 1996; Whitney et al., 1996). Therefore, despite its ubiquitous expression, the only in vivo requirement for the murine Fancc protein appears to be in the germline.

While the primary molecular defect of FA remains unknown, one hypothesis is that FA proteins play a role in DNA damage repair. This hypothesis is supported by the hypersensitivity to DNA cross-linking agents that is a hallmark of the FA phenotype. Moreover, plasmid ligation assays in FA lymphoblast lines show specific defects in repair of coding joints during in vitro $\mathrm{V}(\mathrm{D}) \mathrm{J}$ recombi-

*Correspondence to: Robert E. Braun, Ph.D, Department of Genetics, Box 357360, 1959 NE Pacific, University of Washington, Seattle, WA 98195. E-mail: braun@u.washington.edu

Contract grant sponsor: National Institutes of Health; Contract grant numbers: HD27215 and HD12629 (to R.E.B.), the latter through a cooperative agreement as part of the Specialized Cooperative Centers Program in Reproduction Research 
nation (Escarceller et al., 1998). Many proteins involved in DNA damage repair play critical roles in meiosis. Patients with ataxia-telangiectasia are frequently infertile (Boder, 1975). Mice with a targeted disruption of the Atm locus are sterile and show defects in leptotene of prophase I (Barlow et al., 1998), while the Brca1 and Rad51 proteins have been shown to co-localize on the developing synaptonemal complex in meiotic cells (Scully et al., 1997). Proteins involved in the mismatch repair pathway, originally characterized as the MutL and MutS proteins of $E$. coli, also have specific defects in recombination during meiosis (Arnheim and Shibata, 1997; Baker et al., 1995, 1996; Edelmann et al., 1999).

Given this body of evidence connecting DNA damage repair in its many forms with the process of meiosis, we hypothesized that the Fancc protein also plays a role in meiosis. To test this hypothesis, we examined expression of FA loci in the developing gonad of wild-type embryos as well as the germ cell complement of Fancc $^{-/-}$embryos at stages during development, both preceding and during meiosis.

Analysis of total RNA recovered from embryonic and fetal gonads was used to determine the expression pattern of three Fanconi anemia genes. RNA was collected from E11.5 genital ridges during the migratory and proliferative phase, E14.5 when females are in meiosis and males are in a $G_{0}$ mitotic arrest, and E16.5 when oocytes are in mid-pachytene of meiosis I. Male and female genital ridges could be identified by morphological differences at the two later time points and were separated for this analysis. A reverse transcription reaction was carried out on the total RNA, followed by PCR to detect Fanca, Fancc, Fancg, and Dazla. The Dazla control indicates that PGCs are present in the preparation. Of the three FA loci examined, message from the Fanca and Fancc loci are present at all time points tested, including both sexes at later time points (Fig. 1). Fancg, however, is present in all samples except the E16.5 fetal ovary preparation. Fanca, Fancc, and Fancg are expressed in time to be involved in the early stages of primordial germ cell development.

Mutant and heterozygote littermates were analyzed at E12.5, E14.5, and E16.5 to examine germ cell numbers at various landmarks in PGC development. The earliest time point, E12.5 was examined using endogenous alkaline phosphatase activity in a whole-mount setting as well as in sections. Germ cell numbers at all time points were quantitated on sections by detection with the antibody to germ cell nuclear antigen 1 , which is expressed specifically in germ cells. At E16.5, PGCs in the female are in the pachytene stage of meiosis, while in the male PGCs are arrested in mitosis. Mutant female embryos show an $89 \%$ reduction in PGC numbers; male embryos have a $67 \%$ reduction (Table 1 ). At 14.5 days of embryonic development, when female PGCs enter into meiosis, the germ cell populations of both sexes has been depleted by $85 \%$ (Table 1, Fig. 2). An earlier time point, E12.5, shows a nearly four-fold reduction of primordial germ cells (Table 1, Figs. 3, 4). This reflects

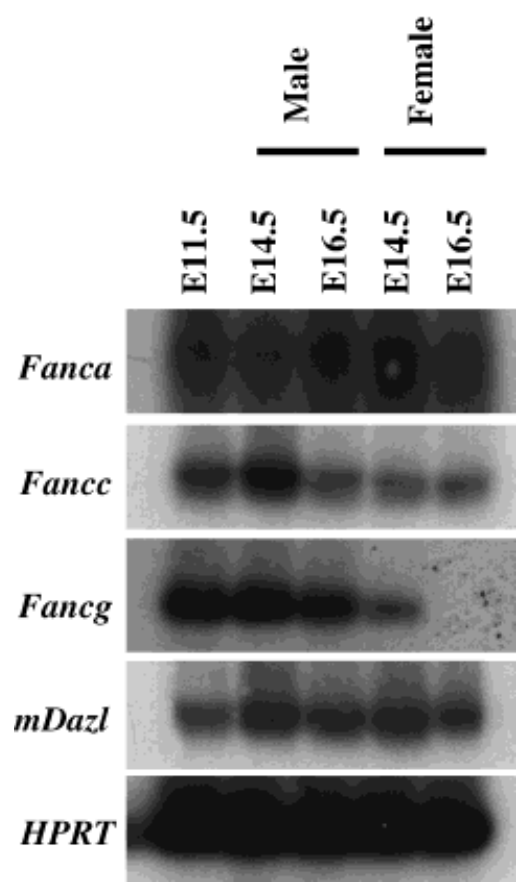

FIG. 1. Fanconi anemia loci are expressed during PGC development. Shown here are Southern blots of RT-PCR reactions probed with gene-specific oligos as described in Materials and Methods.

Table 1

Quantitation of Germ Cell Reduction During PGC Development

\begin{tabular}{llccr}
\hline & & $\begin{array}{c}\text { FancC }^{+/-} \\
\# \pm \text { SE }(\mathrm{n})\end{array}$ & $\begin{array}{c}\text { Fancc }^{-/-} \\
\# \pm \text { SE (n) }\end{array}$ & P-value \\
\hline E12.5 & & & & \\
& Testis & $93 \pm 13(14)$ & $25 \pm 11(10)$ & 0.0002 \\
E14.5 & Ovary & $82 \pm 14(14)$ & $24 \pm 3(9)$ & 0.0006 \\
& & & & \\
& Testis & $466 \pm 18(50)$ & $57 \pm 6(38)$ & $<0.005$ \\
E16.5 & Ovary & $187 \pm 22(41)$ & $26 \pm 4(29)$ & $<0.005$ \\
& Testis & $387 \pm 21(50)$ & $126 \pm 16(43)$ & $<0.005$ \\
& Ovary & $141 \pm 14(46)$ & $16 \pm 4(31)$ & $<0.005$ \\
\hline
\end{tabular}

Average germ cell number per section by genotype at three time points. Reduction in mutant numbers is significant at all time points examined. E12.5 n, number of embryos. E14.5, E16.5 n, number of sections.

germ cell loss prior to completion of migration from the base of the allantois. Analysis of this time point also revealed the striking variability of germ cell numbers both in heterozygote and mutant embryos (Fig. 5). Examination of an earlier time point, E10.5, did not reveal a population of PGCs failing to migrate, suggesting migration occurs normally (data not shown).

The finding of germ cell depletion prior to cell cycle arrest with no apparent fault in migration suggests a defect in proliferation. Mitotic indices of PGCs were assayed at E12.5 by BrdU incorporation (Fig. 6). Mitotic index was calculated by the number of cells positive for both GCNA-1, indicating a germ cell, and BrdU, indicat- 
FIG. 2. Germ cell numbers are reduced in E14.5 fetal gonads. Immunocytochemistry with $\alpha$ GCNA-1 to detect PGCs. (a, c, e, g) FancC $^{+-}$; (b, d, f, h) Fancc $^{-1-}$; (a-d) female; (e-h) male; (a, b, e, f) 200×; (c, d, g, h) 400×.

$$
\text { FancC }^{+/-} \quad \text { FancC }^{-/-}
$$

\section{Female}

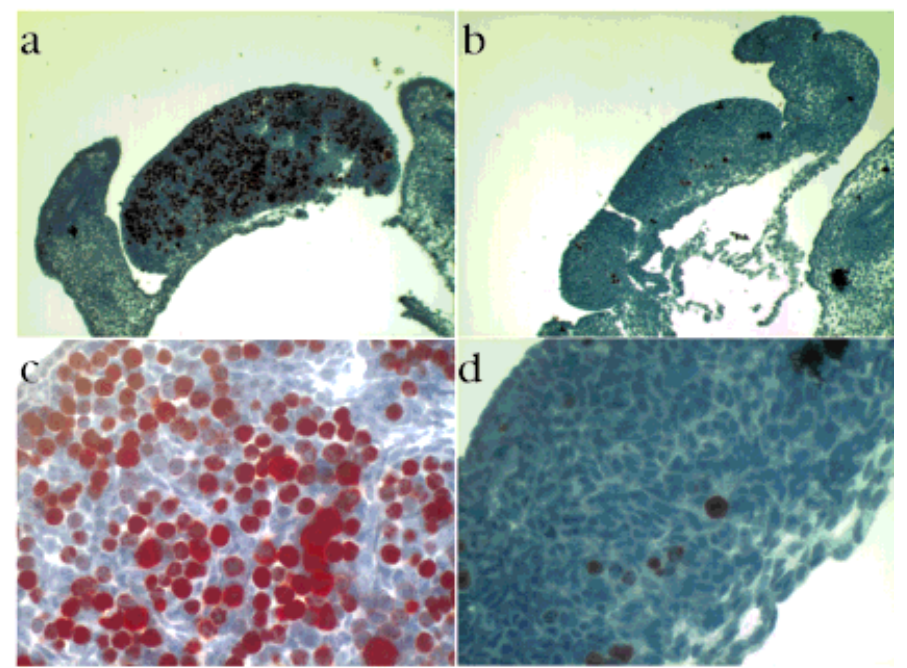

Male

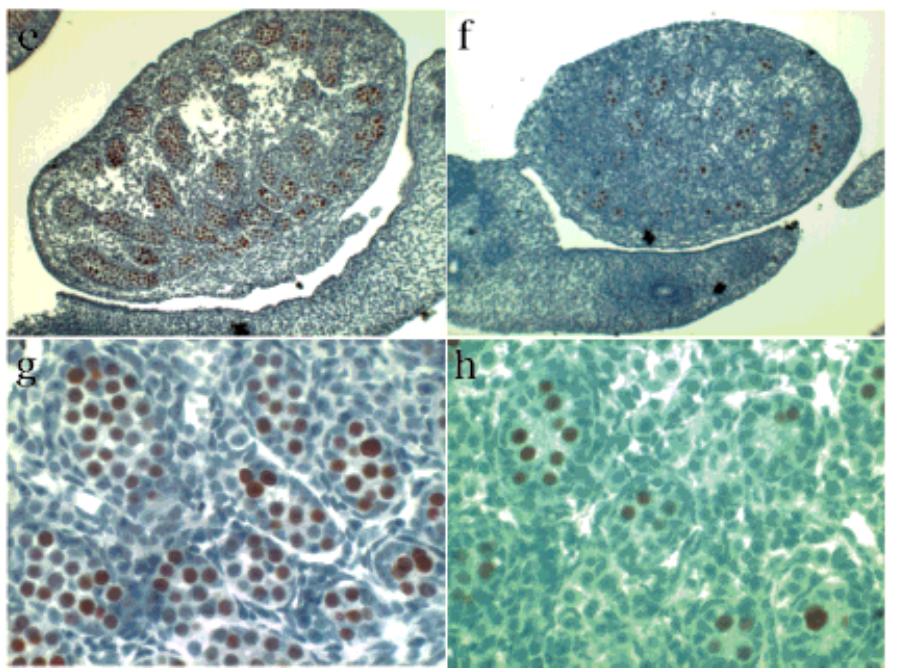

ing DNA synthesis, divided by the total number of GCNA-1 positive cells in a given section. The percent of heterozygous germ cells that were undergoing replication was $23 \%$, while the portion of mutant germ cells replicating was $15 \%$. This represents a $35 \%$ reduction in mitotic index, indicating a severe reduction in germ cell proliferation (Table 2).

Prior to E12.5, the PGC lineage must specify, migrate from the base of the allantois, and proliferate, both during migration and in the genital ridge. Proliferation is reduced in Fancc mutant germ cells, while migration appears to be normal. The described defect precedes the divergence of male and female programs of germ cell development. Subsequent time points show a decreasing proportion of germ cells remaining in mutant females after proliferation ceases. This indicates a defect in survival as well as proliferation in female germ cell development. While this phenotype is different than those of DNA damage repair mutants, it is reminiscent of mutations in growth factor pathways utilized by the developing germline.

Many growth factors are involved in germ cell development. Mutations in steel factor (Sl) and its receptor $c$-kit (W) were originally characterized for defects in germ cell development, pigmentation, and hematopoiesis. These factors are important in PGC survival. The W/Sl mutant phenotypes resemble those of FA, particularly in their pleiotropic effects in several cell lineages. The interleukin/leukemia inhibitory factor (LIF) cytokine family is implicated in survival as well as proliferation in germ cells in vitro (Wylie, 1999). However, LIF and LIF-receptor mutant mice show no germ cell defect, suggesting redundancy of the LIF family of signaling molecules. The similarity in phenotype between Fancc mutants and those in growth-factor pathways implies that the FA proteins may be involved in generation of and response to these signals. The FA proteins have previously been implicated in growth factor 

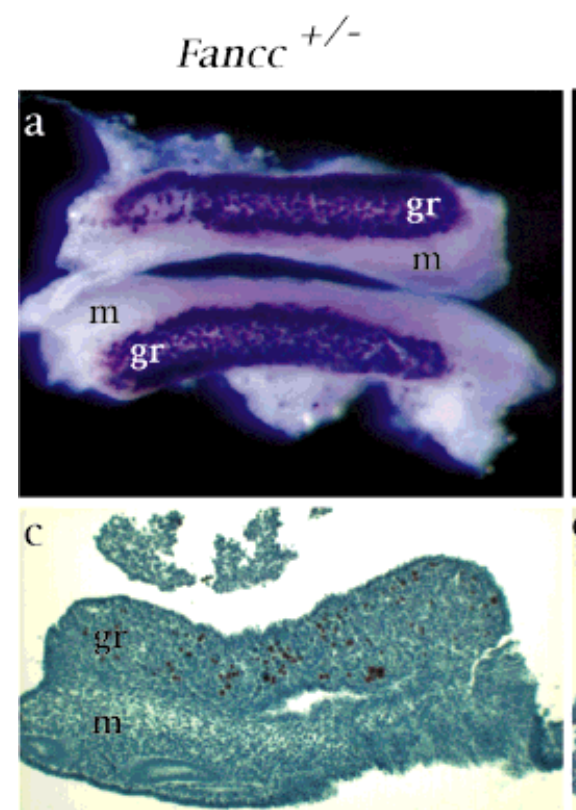

d
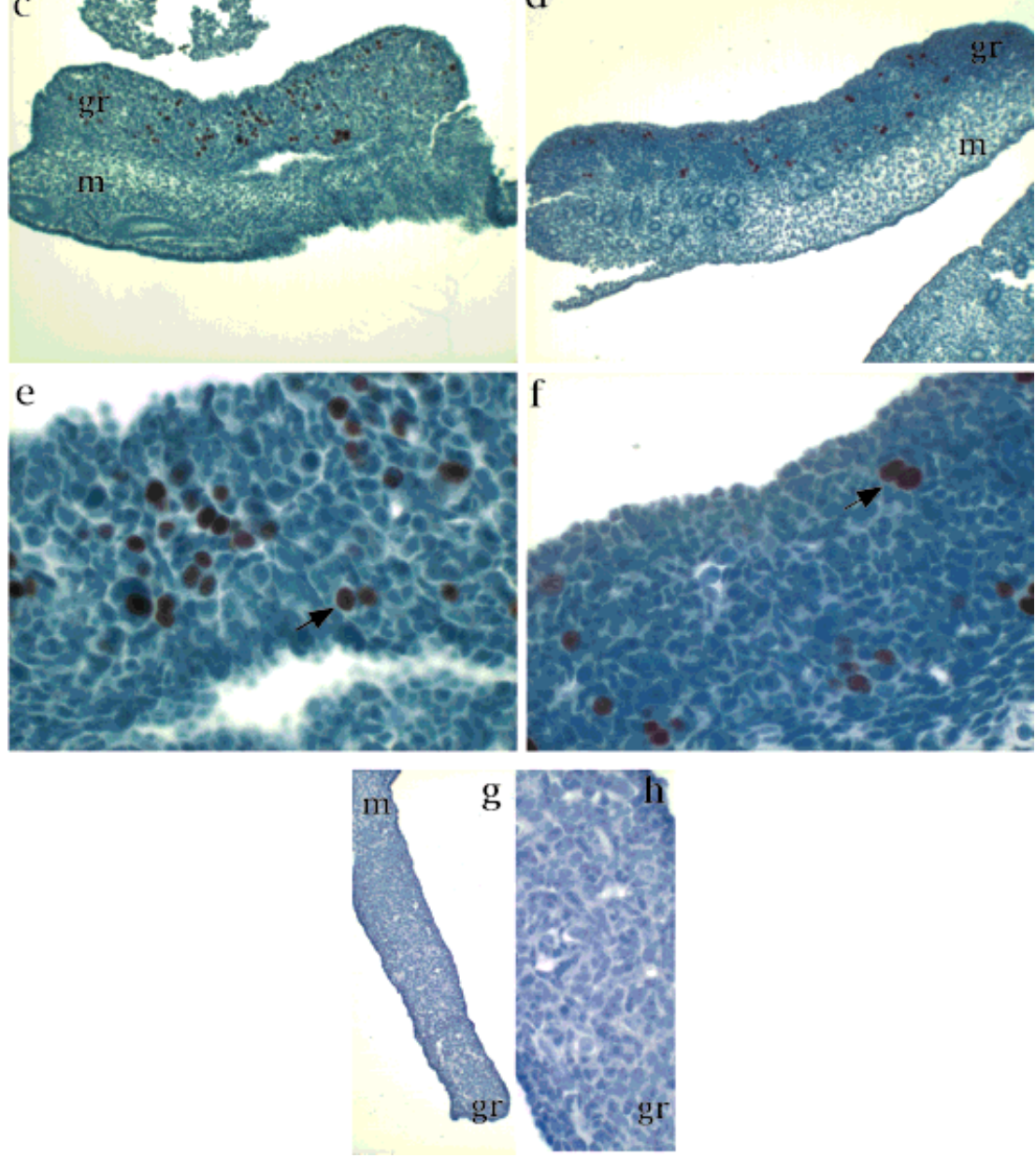

FIG. 3. Embryonic ovaries have a reduction of PGCs by E12.5. (a, c, e, g, h) Fancc ${ }^{+/-}$; (b, d, f) Fancc ${ }^{-\prime-}$. (a, b) Whole-mount genital ridges and mesonephros stained for endogenous alkaline phosphatase activity. (c, d) Immunocytochemistry with $\alpha \mathrm{GCNA}-1$ to detect PGCs, $100 \times$. (e, f) Immunocytochemistry with $\alpha$ GCNA- 1 to detect PGCs, 400 $\times$. (g, h) Immunocytochemistry with no primary antibody, 40×, 200×. m, mesonephros; gr, genital ridge; arrow, PGC. signaling by experiments with human lymphoblast culture (Rosselli et al., 1994, 1995). However, its specific germline function had not been demonstrated prior to the targeted disruption of the murine locus. Further investigation of the cell types expressing Fanconi anemia loci may be helpful in elucidating their involvement in either signal or response.

An alternate hypothesis is that the FA complex functions in a DNA damage monitoring capacity, specifically in the murine germline. Previous studies have shown a lower mutation rate in the germline of young mice com- pared with the rate in the somatic cells (Walter et al., 1998). DNA damage repair is an important function in a somatic cell, but results of faulty repair in these cells has consequences for the cell or the individual alone. Defects of DNA damage repair in the germline reduce the fitness of the next generation and could have specieswide consequences. Through a lineage-specific repair of DNA damage, the Fanconi anemia loci may function to preserve the stability of the genetic information conferred on the next generation. 
FIG. 4. Embryonic testes have a reduction of PGCs by E12.5. (a, c, e) Fancc ${ }^{+/-} ;(\mathbf{b}, \mathbf{d}, \mathbf{f})$ Fancc $^{-1-}$. (a, b) Whole-mount genital ridges and mesonephros stained for endogenous alkaline phosphatase activity. (c, d) Immunocytochemistry with $\alpha$ GCNA- 1 to detect PGCs, 100×. (e, f) Immunocytochemistry with $\alpha \mathrm{GCNA}-1$ to detect PGCs, 400×. m, mesonephros; gr, genital ridge; arrow, PGC.

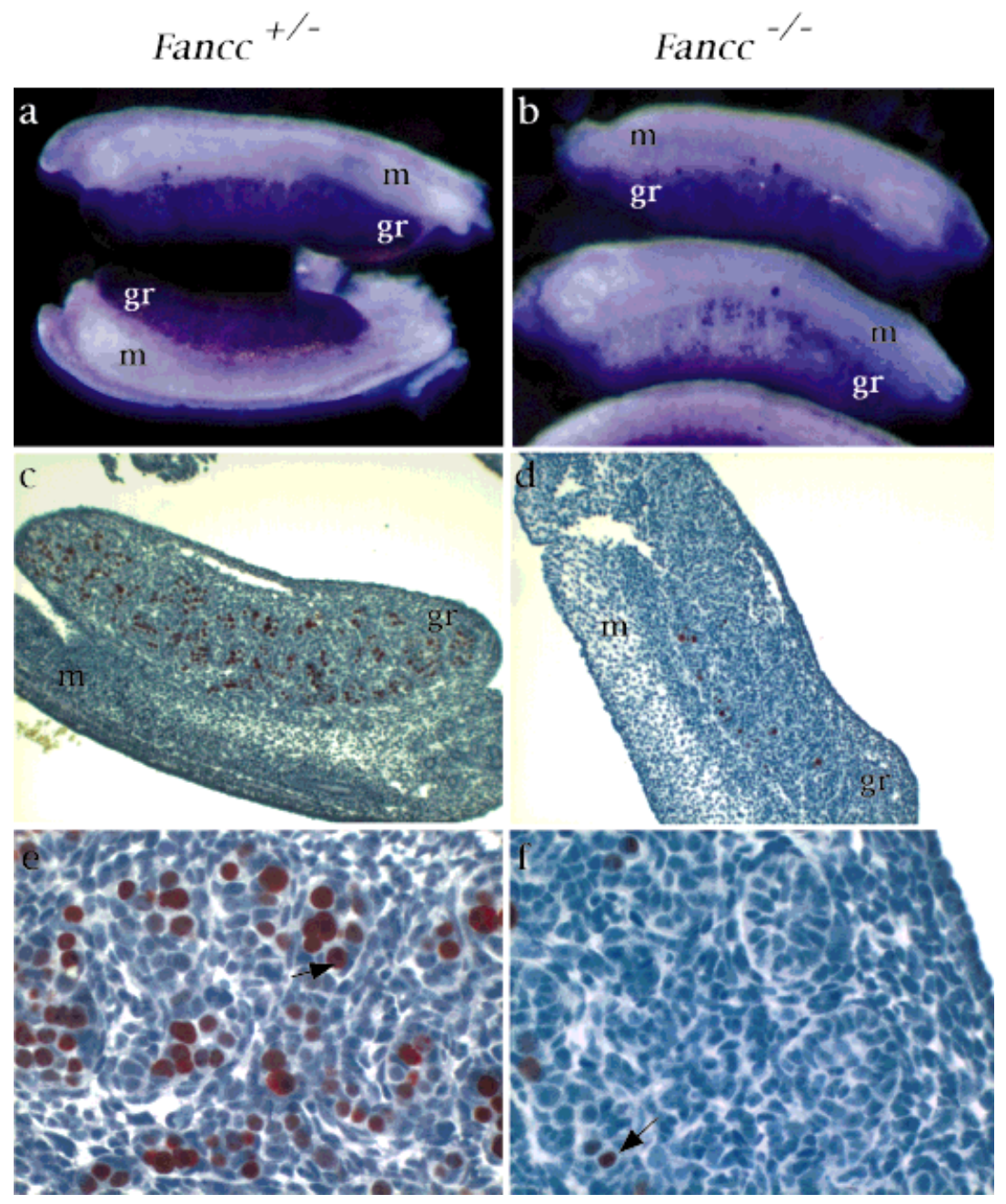

\section{MATERIALS AND METHODS}

To collect fetal gonads for RT-PCR analysis, C57Bl/6 males and females were caged together and the females were checked for copulation plugs to determine time of conception. Embryos were dissected at the appropriate time points. Genital ridges, mesonephros, and a portion of the dorsal mesentery were removed from E11.5 embryos. At E14.5 and E16.5, fetal gonads were dissected along with the mesonephros and grouped by sex. Total RNA was prepared using the Trizol reagent (Gibco BRL) as per manufacturer's instructions. RT-PCR was performed using the Access RT-PCR system (Promega) using the following primers: Fanca (Foe et al., 1996), FAA-F1, GAC TCC CGT GTG GCG TTT AT, FAA-R1, CAG CAC ATG TGG GG CAC TCA; Fancc, JN-16, ACG CGT CGA CCT AGA CCT GGG CTT GCA GCT CC, JN-19, GCC TCT GCT GCA CAT TTC C; Fancg, JN-110, ACA CTG GAA GGG CTT AGG GAA C, JN-111, GTT TGT AAC AGC AAG GTC AGG TCC; Dazla, JN-29, TCG AAC TGG TGT GTC GAA GGG, JN-30, CAA GAG ACA ACT GTC TGT ATG C. The expected sizes of RT-PCR products are 520 bp for
Fanca, 500 bp for Fancc, 359 bp for Fancg, and 780 bp for Dazla. Cycling conditions were $48^{\circ} \mathrm{C}$ for $45 \mathrm{~min}$ and $94^{\circ} \mathrm{C}$ for $2 \mathrm{~min}$ for the reverse transcriptase reaction, followed by 35 cycles of $94^{\circ} \mathrm{C}$ for $30 \mathrm{~s}, 60^{\circ} \mathrm{C}$ for $1 \mathrm{~min}$, and $68^{\circ} \mathrm{C}$ for $1 \mathrm{~min}$, then a final extension at $68^{\circ} \mathrm{C}$ was carried out for 7 min. Reactions were run on a $3 \%$ agarose gel and blotted onto nylon membrane (Hybond). Blots were probed with gene-specific oligos as follows: Fanca, FAA-F1; Fancc, JN-20, AGG AAG CAG CTG AGA GTC CC; Fancg, JN-112, GAT CTT CAA AGG GGC CTC GA; Dazla, JN-35, GAG ACT TAC ATG CAG CCT CC. Sequence for the murine Fancg locus was taken from an IMAGE clone EST in GENBANK, accession number AI604722.

Histological analysis and germ cell numbers were obtained on sections of fetal gonads from $\mathrm{Fancc}^{+-}$females crossed to $\mathrm{Fancc}^{-1-}$ males from a mixed 129 and C57BL/6. At E12.5, E14.5, or E16.5, pregnant females were sacrificed and embryos collected. Embryo heads were used for PCR genotyping; genital ridges and mesonephros were dissected and fixed in $4 \%$ paraformaldehyde overnight. The tissues were then dehydrated for 

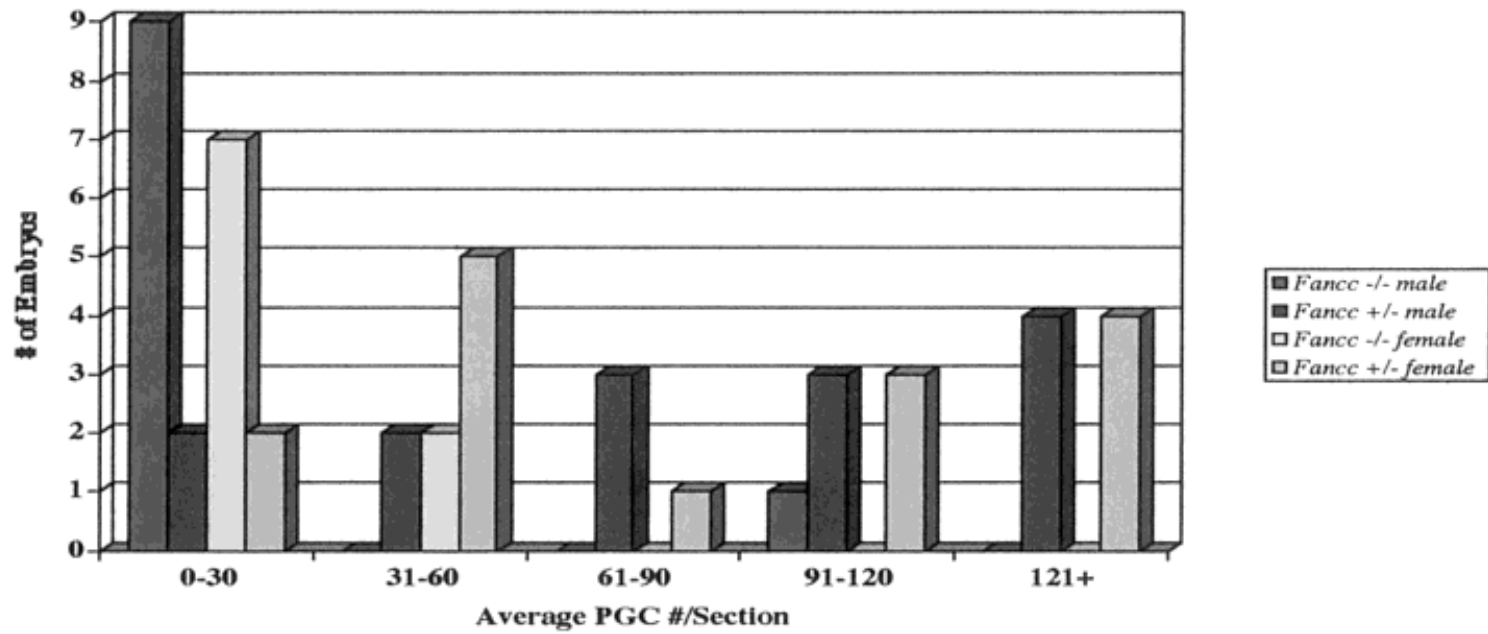

FIG. 5. Variability of germ cell numbers at E12.5. The average number of PGCs per section through a single tissue was calculated and grouped to show the variability amongst the embryos of both genotypes.
FancC $^{+/-}$
Fancc $^{-/-}$

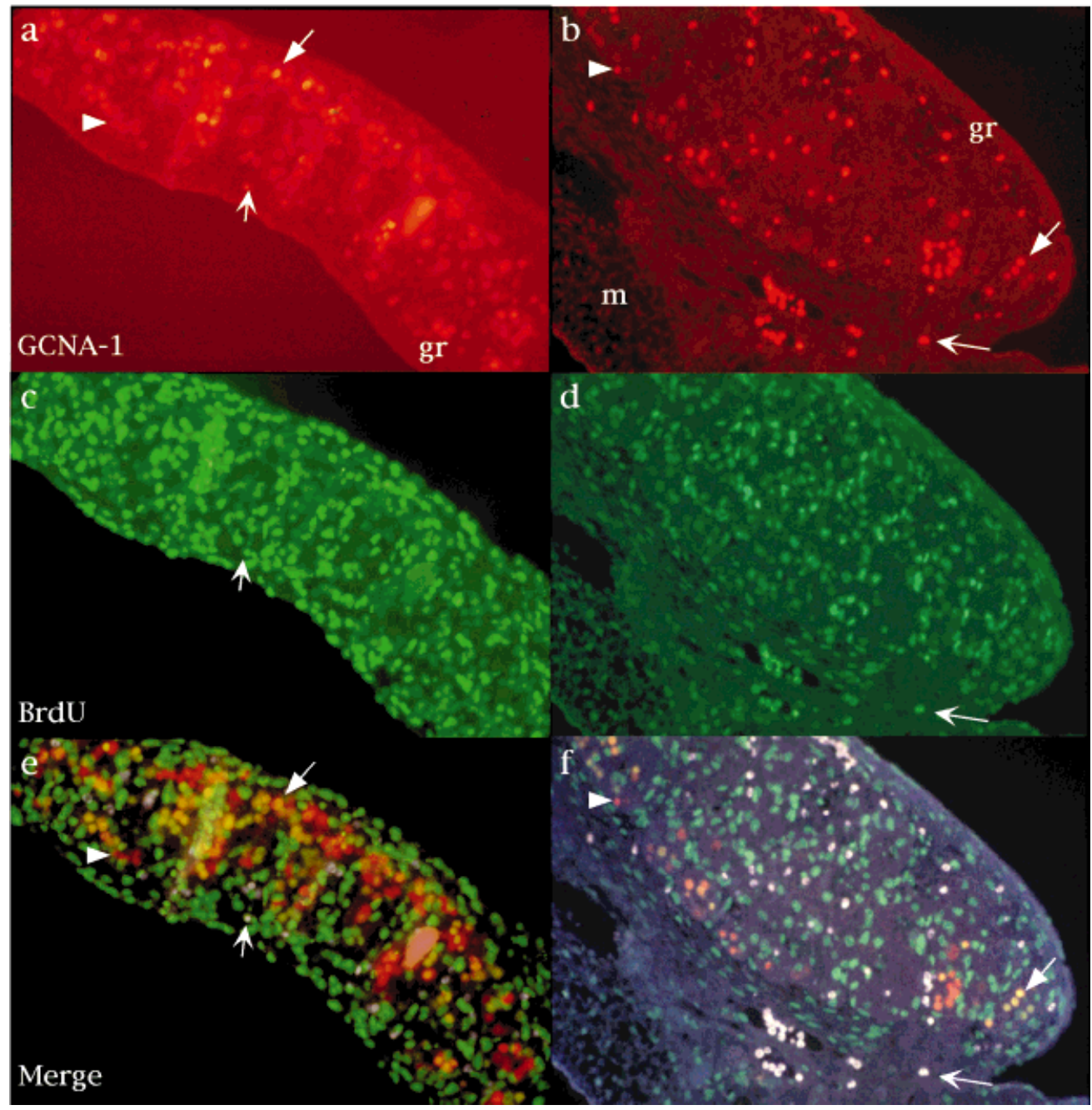

FIG. 6. Proliferation is reduced in E12.5 PGCs. (a, c, e) Fancc ${ }^{+/-}$; (b, d, f) Fancc ${ }^{-1-}$. (a, b, e, f) $\alpha \mathrm{GCNA}-1$ to detect PGCs (red). (c, d, e, f) $\alpha \mathrm{BrdU}$ to detect mitotic cells (green). Closed arrow, mitotic PGC; arrowhead, nonmitotic PGC; open arrow, autofluorescent cell. 
Table 2

Reduced Proliferation of PGCs in Fancc ${ }^{-1-}$ at E12.5

\begin{tabular}{lccc}
\hline & Fancc $^{+/-}$ & Fancc $^{-/-}$ & P-value \\
\hline Average & $23 \pm 3$ & $15 \pm 1$ & 0.00003 \\
n (sections) & 31 & 31 & \\
n (PGC) & 5646 & 1170 & \\
\hline
\end{tabular}

several hours in $70 \%, 80 \%, 95 \%$, and absolute ethanol before being grouped by genotype and embedded in paraffin blocks. Blocks were cut into 10-micron sections throughout the entire tissue. An antibody to GCNA-1 (Enders and May, 1994) was used to detect primordial germ cells on every fifth section. Tissues were counterstained with hematoxylin. The number of PGCs on a saggittal section was counted for sections throughout a single genital ridge at E12.5. E14.5 and E16.5 numbers were obtained by averaging the number of germ cells per section counted on the specified number of random sections. The average number of germ cells per section was used as the test statistic for a Mann-Whitney U test for small sample sizes to determine statistical significance.

Alkaline phosphatase treatment was performed on whole genital ridges and mesonephros. The tissues were fixed in absolute ethanol overnight and rehydrated in distilled water followed by staining with NBT-BCIP solution (Roche).

Tissue samples for mitotic index calculation were obtained from pregnant females injected with $50 \mathrm{ug} / \mathrm{g}$ body weight BrdU (Amersham) intraperitoneally. After $2 \mathrm{~h}, \mathrm{fe}-$ males were sacrificed and genital ridges/mesonephroi were collected as above. Germ cells were detected by antibodies to GCNA-1, and antibodies to BrdU detected mitotic cells. Antigen retrieval was required to reveal the BrdU epitope (Bancroft and Stevens, 1996). After rehydration, paraffin sections were incubated in $50 \%$ formamide, $1 \times$ SSC, $0.1 \%$ Tween- 20 at $70^{\circ} \mathrm{C}$ for $30 \mathrm{~min}$, then boiled for $10 \mathrm{~min}$ in $10 \mathrm{mM}$ citric acid, $\mathrm{pH}$ 6.0. The sections were treated with standard immunohistochemistry protocols. The mitotic index was calculated as the percentage of GCNA-1-positive cells that were also positive for BrdU and used as a test statistic for the Student's $t$-test.

\section{ACKNOWLEDGMENTS}

The authors thank Dr. G. Enders for the GCNA1 antibody.

\section{LITERATURE CITED}

Arnheim N, Shibata D. 1997. DNA mismatch repair in mammals: role in disease and meiosis. Curr Opin Genet Dev 7:364-370.

Baker SM, Bronner CE, Zhang L, Plug AW, Robatzek M et al. 1995. Male mice defective in the DNA mismatch repair gene PMS2 exhibit abnormal chromosome synapsis in meiosis. Cell 82:309-319.

Baker SM, Plug AW, Prolla TA, Bronner CE, Harris AC et al. 1996. Involvement of mouse Mlh1 in DNA mismatch repair and meiotic crossing over [see comments]. Nature Genet 13:336-342.

Bancroft JD, Stevens A. 1996. Theory and practice of histological techniques. New York: Churchill Livingstone. Pages.
Barlow C, Liyanage M, Moens P, Tarsounas M, Nagashima K et al. 1998. Atm deficiency results in severe meiotic disruption as early as leptonema of prophase I. Development 125:4007-4017.

Boder E. 1975. Ataxia-telangiectasia: some historic, clinical and pathologic observations. Birth Defects Orig Artic Ser 11:255-270.

Carreau M, Gan O, Liu L, Doedens M, McKerlie C et al. 1998. Bone marrow failure in the Fanconi anemia group $\mathrm{C}$ mouse model after DNA damage. Blood 91:2737-2744.

Chen M, Tomkins DJ, Auerbach W, McKerlie C, Youssoufian $\mathrm{H}$ et al. 1996. Inactivation of $\mathrm{Fac}$ in mice produces inducible chromosomal instability and reduced fertility reminiscent of Fanconi anaemia. Nature Genet 12:448-451.

De Felici M, McLaren A. 1982. Isolation of mouse primordial germ cells. Exp Cell Res 142:476-482.

de Winter J, Waisfisz Q, Rooimans M, van Berkel C, Bosnoyan Collins L et al. 1998. The Fanconi anaemia group G gene FANCG is identical with XRCC9. Nature Genet 20:281-283.

Edelmann W, Cohen P, Kneitz B, Winand N, Lia M et al. 1999. Mammalian MutS homologue 5 is required for chromosome pairing in meiosis. Nature Genet 21:123-127.

Enders GC and May JJ. 1994. Developmentally regulated expression of a mouse germ cell nuclear antigen examined from embryonic day 11 to adult in male and female mice. Dev Biol 163:331-340.

Escarceller M, Buchwald M, Singleton B, Jeggo P, Jackson S et al. 1998. Fanconi anemia $\mathrm{C}$ gene product plays a role in the fidelity of blunt DNA end-joining. J Mol Biol 279:375-385.

Foe JR, Rooimans MA, Bosnoyan Collins L, Alon N, Wijker M et al. 1996. Expression cloning of a cDNA for the major Fanconi anaemia gene, FAA. Nature Genet 14:488.

Garcia-Higuera I, Kuang Y, Naf D, Wasik JD, Andrea A. 1999. Fanconi anemia proteins FANCA, FANCC, and FANCG/XRCC9 interact in a functional nuclear complex. Mol Cell Biol 19: 4866- 4873.

Krasnoshtein F, Buchwald M. 1996. Developmental expression of the Fac gene correlates with congenital defects in Fanconi anemia patients. Hum Mol Genet 5:85-93.

Kupfer GM, Naf D, Suliman A, Pulsipher M, D'Andrea AD. 1997. The Fanconi anaemia proteins, FAA and FAC, interact to form a nuclear complex. Nature Genet 17:487-490.

Lawson K, Dunn N, Roelen B, Zeinstra L, Davis A et al. 1999. Bmp4 is required for the generation of primordial germ cells in the mouse embryo. Genes Dev 13:424-436.

Lawson KA, Hage WJ. 1994. Clonal analysis of the origin of primordial germ cells in the mouse. Ciba Found Symp 182:68-84.

Matsui Y, Toksoz D, Nishikawa S, Nishikawa S, Williams D et al. 1991. Effect of Steel factor and leukaemia inhibitory factor on murine primordial germ cells in culture. Nature 353:750-752.

McLaren A. 1984. Meiosis and differentiation of mouse germ cells Symp Soc Exp Biol 38:7-23.

Rosselli F, Ridet A, Soussi T, Duchaud E, Alapetite C et al. 1995. p53-dependent pathway of radio-induced apoptosis is altered in Fanconi anemia. Oncogene 10:9-17.

Rosselli F, Sanceau J, Gluckman E, Wietzerbin J, Moustacchi E. 1994. Abnormal lymphokine production: a novel feature of the genetic disease Fanconi anemia. II. In vitro and in vivo spontaneous overproduction of tumor necrosis factor alpha. Blood 83:12161225

Scully R, Chen J, Plug A, Xiao Y, Weaver D et al. 1997. Association of BRCA1 with Rad51 in mitotic and meiotic cells. Cell 88:265-275.

Strathdee CA, Gavish H, Shannon WR, Buchwald M. 1992. Cloning of cDNAs for Fanconi's anaemia by functional complementation. Nature 358:434

Walter C, Intano G, McCarrey J, McMahan C, Walter R. 1998. Mutation frequency declines during spermatogenesis in young mice but increases in old mice. Proc Natl Acad Sci USA 95:10015-10019.

Wevrick R, Clarke CA, Buchwald M. 1993. Cloning and analysis of the murine Fanconi anemia group C cDNA. Hum Mol Genet 2:655662.

Whitney M, Royle G, Low M, Kelly M, Axthelm M et al. 1996. Germ cell defects and hematopoietic hypersensitivity to gamma-interferon in mice with a targeted disruption of the Fanconi anemia $\mathrm{C}$ gene. Blood 88:49-58.

Wylie C. 1999. Germ cells. Cell 96:165-174. 